\title{
Continuity of care and rapid access: the potential impact of appointment systems*
}

\author{
Navjot Gill and George K. Freeman Department of Primary Care and Social Medicine, Imperial College \\ London, UK
}

\begin{abstract}
In recent years government emphasis on improving access times in general practice has centred on a target of 48-hour access to a doctor. Attempts to achieve this by changing appointment systems may threaten relationship continuity of care, another valued feature of general practice. Now the recent primary care White Paper proposes financial incentives for both these aspects of care. We studied two contrasting booking systems in three large inner London group practices using a one page questionnaire distributed to consecutive patients in the waiting rooms. While most patients in the socalled 'advanced access' practice were seen very quickly, fewer patients, especially those with chronic conditions, were able to see their chosen doctor than in two practices offering more scope for booking appointments ahead. This preliminary study in an inner-city area supports other work, as well as anecdotal reports, suggesting that unbalanced emphasis on rapid access may impair patients' scope to see their practitioner of choice.
\end{abstract}

Received: March 2006; accepted: February 2007

\section{Introduction}

Setting 48-hour access targets for patients to see general practitioners (GPs) was a government response to widespread evidence of patient dissatisfaction with access delays in primary care (Department of Health, 2001), but relationship (or relational) continuity of care (seeing the same, chosen doctor) (Haggerty et al., 2003) is another important element of primary care, which is associated with increased patient satisfaction (Hjortdahl and Laerum, 1992). The scope for conflict between these two desirable aspects of practice has at last

Address for correspondence: Prof George K. Freeman, Department of Primary Care and Social Medicine, 3rd floor, The Reynolds Building, St Dunstan's Road, London W6 8RP, UK. Email: g.freeman@ic.ac.uk

\footnotetext{
* This study was carried out while NG was undertaking her BSc in Social medicine at Imperial College, and while GKF was Professor of General Practice.
}

been recognized in the recent primary care white paper (Department of Health, 2006).

We know that patients who prioritize quick access to consultation appointments tend to be younger, have minor problems and a recent onset of illness or feel too ill to wait any longer (Sweeney and Gray, 1995; Salisbury et al., 2002). Quicker access should help these patients. But patients with chronic illness like to see the same doctor as well as being seen quickly (Stoddart et al., 2003). The access targets introduced in England ignore the issue of choice of doctor. Practices responded to the 48-hour targets in a variety of ways. Some severely limited the availability of pre-booked appointments and a study by Windridge et al. reported patients who felt distressed because these new appointments restricted their ability to exercise choice (Windridge et al., 2004). We aimed to investigate how limiting the option of advance booking affected patients' scope to choose whom they see. We looked at two contrasting booking systems to see which type better accommodated the preferences of patients. We chose 
larger practices as practice size has been inversely correlated with patients feeling enabled and knowing their doctor well (Howie et al., 1999). The time frame of a student project (12 weeks) allowed us to study three large local practices.

\section{Setting and methods}

We studied three of the largest group practices in a West London Primary Care Trust (Hammersmith and Fulham), the fourth declined to participate. This is an inner-city urban area where practice populations overlap, so that patients have a choice of practices. The area is characterized by a wide range of cultures and social classes. Number of full time doctors and registered patients were:

- Practice A: six doctors for 8000 patients

- Practice B: seven doctors for 11000 patients

- Practice C: eight doctors for 12400 patients.

Practices A and B used similar appointment systems. They encouraged patients to book appointments by telephone. All patients wanting to be seen earlier than the available appointments were then telephoned by one 'duty' or 'triage' doctor who would negotiate advice, a prescription, a later appointment, or a same-day consultation - usually with themselves, the duty doctor. Thus patients wishing to be seen urgently normally had no choice of doctor.

A system of so-called advanced access was strongly encouraged by the Department of Health at this time. It was developed in the USA and a key concept was to do 'today's work today' to avoid building up waiting times. Practice $\mathrm{C}$ operated what they described as an 'advanced access' appointment system. Only a limited number of appointments were bookable in advance. These were early morning and late afternoon and could be booked up to one week ahead. They were known as the 'commuter slots', being aimed at people living locally but working elsewhere. All other consulting times were reserved for same-day booking; patients had to telephone from 8.15 to $9.15 \mathrm{a} . \mathrm{m}$. for a morning appointment and 2 to 3 p.m. for an afternoon one.

NG collected the data over six weeks, two weeks in each practice in succession. She handed out preconsultation questionnaires in the waiting room to consecutive waiting patients during a 9 a.m. to
5 p.m. time frame from Monday to Friday. She was thus present when patients gave their responses, but not directly involved. All available patients were approached during the two-week data collection period until there were over 200 responses from each practice. The one-page questionnaire had been devised in Australia (J. Sturmberg, Personal communication, see Appendix). It was piloted in London in seven face-to-face interviews. The only significant change needed was the invitation for patients to add free text comments on the back. There were nine groups of questions:

- patient demography

- whether the patient saw the doctor of their choice

- health self-rating

- reason for today's consultation: new/urgent problem/longstanding physical problem, etc.

- how long they had to wait for the appointment

- their choice of doctor: for example, only doctor available/only doctor I ever see/I don't mind which doctor I see

- whether they had a usual doctor

- how well their usual doctor knew their medical history, etc.

- how much they trusted their usual doctor.

Patients were invited to add free text comments on the blank reverse of the A4 sheet.

We entered results into SPSS version 12 and made comparisons between groups using the Chisquared test and $95 \%$ confidence intervals.

The Riverside Local Research Ethics Committee approved this study.

\section{Results}

We handed out 763 questionnaires. A small proportion of patients were unable or reluctant to complete these and we collected 651 (85\%). Some respondents did not answer every question so denominators of some groups vary a little. We found no significant differences between the three practices in patient demography or self-reported general health status.

Responses from patients in practices $\mathrm{A}$ and $\mathrm{B}$ were closely similar and we combined them for this report. Those from practice $\mathrm{C}$ were significantly different in a variety of ways as seen in Table 1. 
Table 1 Patient responses in practices A \& B compared with those from practice C. 95\% confidence intervals for the percentage differences are given

\begin{tabular}{|c|c|c|c|c|c|c|}
\hline \multirow[b]{2}{*}{ Question } & \multicolumn{2}{|c|}{$\begin{array}{l}\text { Patients in } \\
\text { practices A \& B }\end{array}$} & \multicolumn{2}{|c|}{$\begin{array}{l}\text { Patients in } \\
\text { practice C }\end{array}$} & \multirow{2}{*}{$\begin{array}{l}\text { Difference } \\
\text { A \& B versus C } \\
\%\end{array}$} & \multirow{2}{*}{$\begin{array}{l}95 \% \mathrm{Cl} \\
\text { for difference } \\
\%\end{array}$} \\
\hline & $n$ & $\%$ & $n$ & $\%$ & & \\
\hline \multicolumn{7}{|l|}{$\begin{array}{l}\text { Today I have seen the doctor of my } \\
\text { choice }\end{array}$} \\
\hline All patients & $273 / 432$ & 63 & $89 / 218$ & 41 & 22 & $14-30$ \\
\hline $\begin{array}{l}\text { Patients with new/urgent physical } \\
\text { problem }\end{array}$ & $54 / 143$ & 38 & $22 / 80$ & 28 & 10 & -2 to +22 \\
\hline Long-standing physical problem & $97 / 126$ & 77 & $25 / 52$ & 48 & 29 & $13-43$ \\
\hline $\begin{array}{l}\text { Preventive health advice/screening } \\
\text { test }\end{array}$ & $47 / 73$ & 64 & $14 / 27$ & 52 & 12 & -8 to +33 \\
\hline Certificate/report or similar & $29 / 36$ & 81 & $12 / 28$ & 43 & 38 & $14-57$ \\
\hline Problem with family, etc. & $2 / 4$ & 50 & $1 / 4$ & 25 & 25 & -32 to +66 \\
\hline $\begin{array}{l}\text { Problem with depression/anxiety/ } \\
\text { being unable to cope }\end{array}$ & $37 / 42$ & 88 & $12 / 20$ & 60 & 28 & $6-50$ \\
\hline Today I will see the doctor for: & 424 & & 211 & & & \\
\hline New/urgent physical problem & 143 & 34 & 80 & 38 & 4 & -4 to +12 \\
\hline Long-standing physical problem & 126 & 30 & 52 & 25 & 5 & -2 to +12 \\
\hline $\begin{array}{l}\text { Preventive health advice/ } \\
\text { screening test }\end{array}$ & 73 & 17 & 27 & 13 & 5 & -2 to +10 \\
\hline Certificate/report or similar & 36 & 8 & 28 & 13 & 5 & $0-10$ \\
\hline Problem with family, etc. & 4 & 1 & 4 & 2 & 0 & -1 to +4 \\
\hline $\begin{array}{l}\text { Problem with depression/anxiety/ } \\
\text { being unable to cope }\end{array}$ & 42 & 10 & 20 & 9 & 0 & -5 to +5 \\
\hline How many days to get appointment & 412 & & 212 & & & \\
\hline Zero days & 104 & 25 & 171 & 81 & 55 & $48-62$ \\
\hline One day & 20 & 5 & 13 & 6 & 1 & -2 to +6 \\
\hline Two days & 32 & 8 & 9 & 5 & 3 & -1 to +7 \\
\hline Three plus days & 256 & 62 & 19 & 11 & 53 & $46-58$ \\
\hline $\begin{array}{l}\text { In relation to THIS consultation (tick } \\
\text { the one that best describes your } \\
\text { situation) }\end{array}$ & 430 & & 217 & & & \\
\hline $\begin{array}{l}\text { This is the only doctor I could } \\
\text { see today }\end{array}$ & 101 & 23 & 72 & 33 & 10 & $2-17$ \\
\hline $\begin{array}{l}\text { This doctor is the only doctor I ever } \\
\text { see and/or I wait to see him/her. }\end{array}$ & 145 & 34 & 38 & 18 & 16 & $9-23$ \\
\hline I don't mind which doctor I see & 147 & 34 & 92 & 42 & 8 & $0.3-16$ \\
\hline Other response & 37 & 9 & 15 & 7 & 2 & -3 to +6 \\
\hline $\begin{array}{l}\text { This doctor was recommended to } \\
\text { me by a friend/family }\end{array}$ & 7 & & 3 & & & \\
\hline $\begin{array}{l}\text { This doctor was recommended to } \\
\text { me for my particular problem }\end{array}$ & 16 & & 7 & & & \\
\hline $\begin{array}{l}\text { For my problem today, I want to see } \\
\text { a doctor who doesn't know me }\end{array}$ & 7 & & 1 & & & \\
\hline $\begin{array}{l}\text { I see this doctor because I want a } \\
\text { second opinion from my usual doctor }\end{array}$ & 2 & & 2 & & & \\
\hline $\begin{array}{l}\text { I see this doctor because I want a } \\
\text { second opinion from another doctor }\end{array}$ & 5 & & 2 & & & \\
\hline Do you have a usual doctor? & 433 & & 218 & & & \\
\hline Yes & 311 & 72 & 148 & 68 & 4 & -3 to +12 \\
\hline Respondent added a free text comment & 433 & & 218 & & & \\
\hline Yes & 18 & 4 & 22 & 10 & 6 & $2-10$ \\
\hline
\end{tabular}


Patients in practices A and B were more likely to be seeing their doctor of choice than those in practice $\mathrm{C}$, particularly if they had a chronic medical condition. On the other hand they were much less likely to be seen on the day of their request.

Similarly practice $\mathrm{C}$ patients were less likely to be seeing a doctor that they 'only ever see' or 'wait to see' and more of them reported that they 'didn't mind' which doctor they see. Patients were also able to add comments. Only nine patients each from practices $\mathrm{A}$ and $\mathrm{B}$ added comments whereas $22 \mathrm{C}$ patients did so. Box 1 shows some examples to represent the range of opinion.

\section{Box 1 Comments volunteered in free text by patients}

\section{Practice A}

'I value knowing that I have a doctor who knows my history and I try to visit her each time. Often the clinic is unable or unwilling to schedule me with her. I understand the difficulties with diaries but I would urge that seeing the same doctor is made a priority.'

(Female, 29 years old, attending for health advice/screening test)

'I think it would help if the same doctor saw me every time I visited the GP. This way I would get to know them and they would get to know me, so there would be more trust.'

(Male, 18 years old, attending for a new physical problem)

'Recently, I saw a doctor that I didn't like and I don't want to see him but I don't mind seeing any of the other doctors'

(Female, 35 years old, attending for a new physical problem)

'I have chosen to see a female doctor due to a 'female' problem.'

(Female, 25 years old, attending for a certificate/report)

'I have seen all of the doctors in this practice and I consult with different doctors for different matters. Therefore, I have many 'usual' doctors.'

(Female, 44 years old, attending for health advice/screening test)

\section{Practice B}

'My only criticism of what I think is an excellent NHS practice, is that you often have to wait ten days or thereabouts to see 'your' doctor.'

(Male, 71 years old, attending for a chronic physical problem)

'I see any doctor available and feel most of them know me. I feel confident with them all.'

(Female, 53 years old, attending a chronic physical problem)

'The doctors that I prefer to see are women because many of the problems I have had are 'women problems'. I have become familiar with them and feel comfortable with them and so where possible I would always choose to see them ... I feel more relaxed with a woman.'

(Female, 39 years old, attending for a new physical problem) 
'I'd rather see Dr X or Dr Y, however, sometimes it can take well over a week to get a suitable appointment with them. Therefore, I often have to settle for a doctor that doesn't know very much about me, which can be a disappointment and feels quite impersonal at times.'

(Female, 28 years old, attending for a chronic physical problem)

'I have seen most GPs in this practice at different times. I would be happy to see any of them. I am sticking with Dr X concerning this particular ailment.'

(Male, 35 years old, attending for a chronic physical problem)

\section{Practice C}

'I would usually ask for a female doctor and would prefer to see the same doctor but, I would rather see any doctor than not get an appointment at all.'

(Female, 25 years old, attending for a new physical problem)

'In general, I do not mind which doctor I see, although on occasion I may prefer to see a female doctor for personal issues.'

(Female, 27 years old, attending for a chronic physical problem)

'I thought you just take a doctor that you're given and ask to move if you really don't like them.'

(Female, 29 years old, attending for a chronic physical problem)

'I am quite happy to see whichever doctor is available unless I have a long-standing illness.'

(Female, 28 years old, attending for a new physical problem)

'I have no 'usual' doctor but I feel that whoever I see is pretty skilled at making a quick assessment from my notes. Gone are the days when I feel a particular doctor 'knows' me. I no longer see this as a viable possibility under the NHS. I have been a patient at this practice for over twenty years.'

(Female, 59 years old, attending for a new physical problem)

'For those of us who keep appointments the new system of no advance booking does not work. It often results in having to see a different doctor to your own.'

(Male, 56 years old, attending for a chronic physical problem).

'With the current appointment booking system at this practice, one has to see the GP on duty. The concept of a 'usual' doctor has disappeared.'

(Female, 61 years old, attending for a certificate/report)

'The present arrangement is certainly not working! I find great difficulty in seeing the doctor I want to see. Can we please go back to the old system or update the present system.'

(Male, 69 years old, attending for a chronic physical problem)

'Some of the doctors in this surgery are very good. There are others that I do not like to see but sometimes I am forced to see these doctors when they are the only ones available.'

(Female, 28 years old, attending for a new physical problem) 


\section{Discussion}

This study is one of the first to directly compare the influence that different appointment systems may be having on continuity of care. The findings are consistent with an interpretation that a policy of severely restricting the scope for patients to book appointments ahead (as in practice $\mathrm{C}$ ) indeed limits their ability to see their doctor of choice. But at the same time, a high rate of sameday access was being achieved.

This study is small scale and in one area of London. Time limitations limited the number of observation sessions, thus the study size was pragmatic, rather than based on a prior power calculation. Our method precluded gathering information about non-respondents, who may of course have held different views although their number was relatively few. Thus findings need confirmation in larger scale work of this kind. While the study design did not allow direct comparison of patients' satisfaction, the higher number and content of the comments written in by respondents in practice $\mathrm{C}$ could suggest that these patients have more concerns regarding this booking system.

Patients in practices A and B appear to have been able to achieve a better balance between personal continuity and quick enough access. This is not a criticism of the concept of 'advanced access', but rather of the way it may sometimes have been implemented by severely limiting the opportunity for patients to choose to book in advance with their practitioner of choice. In these circumstances it must be hard for patients to plan their lives when follow up of a chronic problem is needed. Other work suggests that patients elsewhere in England share these concerns (Windridge et al.,2004). It is likely also that some patients who do not actively seek to see the same doctor might yet benefit from this (Sweeney and Gray, 1995; Boulton et al., 2006).

The National Primary Care Development Team (2005) does not advocate the use of an appointment system that restricts patient's abilities to book appointments in advance, indeed it now expressly states that advance booking is a part of advanced access. Now the latest White Paper (Department of Health, 2006) has gone further by proposing (para 3.51) a financial incentive for practices to give patients 'the opportunity to consult their preferred practitioner (while recognizing that this may mean waiting longer)'. This has not been implemented at the time of writing.

Advanced access as described by its advocates should not limit, but rather enhance interpersonal continuity. Crucially, there must be adequate capacity so that choice is available (Murray and Berwick, 2003). But the NHS has not facilitated the provision of additional capacity and it may not be appropriate to adopt a model based on the USA's very different healthcare system (Pickin et al., 2004; Salisbury, 2004). If achieving rapid access and choice of practitioner are both to be financially rewarded it will be interesting to see what patients actually experience in future, given that the excess capacity necessary for the realistic operation of choice is unlikely to be widely available.

Wider, more detailed research into the working of access systems and of any financial or other incentives is urgently needed.

\section{Acknowledgements}

We thank all the patients and staff in the three participating practices. We gratefully acknowledge help and encouragement from Dr Joachim Sturmberg in initiating this study and supplying the questionnaire and from Prof. Konrad Jamrozik in criticizing the protocol.

\section{References}

Boulton, M., Tarrant, C., Windridge, K., Baker, R. and Freeman, G.K. 2006: How are different types of continuity achieved? A mixed methods longitudinal study. British Journal of General Practice 56, 749-55.

Department of Health. 2001: The NHS plan: a plan for investment, a plan for reform. London: HMSO.

Department of Health. 2006: Our health, our care, our say: a new direction for community services. HMSO, Cm 6737. Retrieved 14 February 2006 from http://www.dh.gov.uk/ PublicationsAndStatistics/Publications/PublicationsPolicy AndGuidance/PublicationsPolicyAndGuidanceArticle.

Haggerty, J.L., Reid, R.J., Freeman, G.K., Starfield, B.H., Adair, C.E. and McKendry, R.A. 2003: Synthesis of the concept of 'continuity of care' in the health and policy literature. British Medical Journal 327, 1219-21.

Hjortdahl, P. and Laerum, E. 1992: Continuity of care in general practice: effect on patient satisfaction. British Medical Journal 304, 1287-90.

Howie, J.G.R., Heaney, D.J., Maxwell, M., Walker, J.J., Freeman, G.K. and Rai, H. 1999: Quality at general practice 
consultations: cross-sectional survey. British Medical Journal 319, 736-43.

Murray, M and Berwick, D.M. 2003: Advanced access: reducing waiting and delays in primary care. Journal of American Medical Association 289, 1035-40.

National Primary Care Development Team. 2005: Retrieved 14 February 2006 from http://www.npdt.org/Pre-Bookable.pdf.

Pickin, M., O'Cathain, A., Sampson, F.C. and Dixon, S. 2004: Evaluation of advanced access in the national primary care collaborative. British Journal of General Practice 54, 334-40.

Salisbury, C., Manku-Scott, T., Moore, L., Chalder, M. and Sharp, D. 2002: Questionnaire survey of users of NHS walk-in centres: observational study. British Journal of General Practice 52, 554-60.
Salisbury, C. 2004: Does advanced access work for patients and practices? British Journal General Practitioner 54, 330-31.

Stoddart, H., Evans, M., Peters, T.J. and Salisbury, C. 2003: The provision of 'same-day' care in general practice: an observational study. Family Practice 20, 41-47.

Sweeney, K.G. and Gray, D.P. 1995: Patients who do not receive continuity of care from their general practitioner - are they a vulnerable group? British Journal of General Practice $45,133-35$.

Windridge, K., Tarrant, C., Freeman, G.K., Baker, R., Boulton, M. and Low, J. 2004. Problems with a 'target' approach to access in primary care: a qualitative study. British Journal of General Practice 54, 364-66. 


\section{Appendix}

\section{Imperial College}

\section{London}

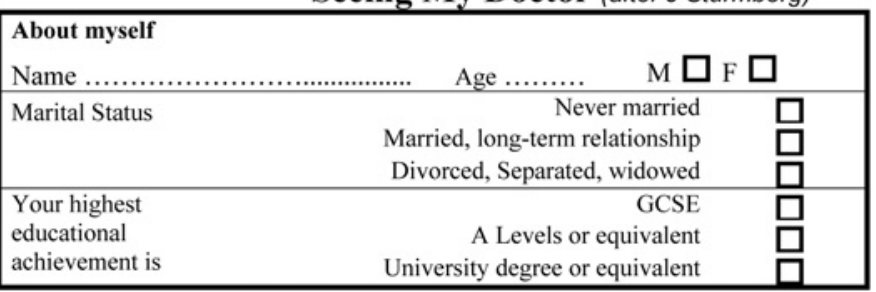

Office Use Only

Practice Code

Doctor Code

No. of visits last

12 months

No. of different

doctors

Consultation

length

In general my health is

\begin{tabular}{|l|}
\hline Today I will see the doctor for (tick $\boldsymbol{A L} \boldsymbol{L}$ that apply) \\
A new/urgent physical problem \\
$\begin{array}{l}\text { A long-standing physical problem } \\
\text { Preventive health advice/screening test }\end{array}$ \\
$\begin{array}{l}\text { A certificate/report or similar } \\
\text { A problem with family/friends } \\
\text { money } \\
\text { Work }\end{array}$ \\
\hline
\end{tabular}

How many days did you wait to get today's appointment? $\quad 0 \quad \square \quad 1 \quad \square \quad 2 \square \square 3+\square$

In relation to THIS consultation (tick the $O N E$ that $B E S T$ describes your situation)

This is the only doctor I am able to see today.

or - This doctor is the only doctor I ever see and/or I wait to see him/her.

or - This doctor was recommended to me by a friend/family.

or - This doctor was recommended to me for my particular problem.

or - For my problem today, I want to see a doctor who doesn't know me.

or - I see this doctor because I want a second opinion from my usual doctor.

or - I see this doctor because I want a second opinion form another doctor.

or - I don't mind which doctor I see.

$\square$
$\square$
$\square$
$\square$
$\square$
$\square$
$\square$
$\square$

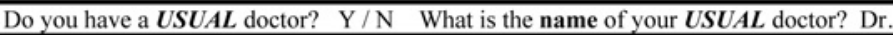

\begin{tabular}{llcc|}
\hline How well does your $U S U A L$ doctor know your medical history, & poorly & fairly & well \\
your worries about your health and your responsibilities at \\
home and at work?
\end{tabular}

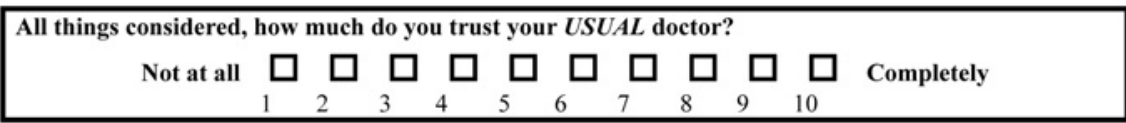

If you have any comments, please write them on the reverse of this sheet. Thank you for your help!

Primary Health Care Research \& Development 2007; 8: 235-242 